\title{
Effects of Ghrelin on iNOS-Derived NO Promoted LPS-Induced Pulmonary Alveolar Epithelial A549 Cells Apoptosis
}

\author{
Mian Zeng ${ }^{\mathrm{a}}$ Chunrong Huanga ${ }^{\mathrm{a}, \mathrm{b}}$ Haichong Zheng ${ }^{\mathrm{a}}$ Qingui Chen ${ }^{\mathrm{a}}$ Wanmei He \\ Yubin Deng ${ }^{c}$ \\ aDepartment of Medical Intensive Care Unit, The First Affiliated Hospital, Sun Yat-Sen University, \\ Guangzhou, 'Department of Intensive Care Unit, The Third Peoples Hospital of Chengdu, Chengdu, \\ 'Research Center of Translational Medicine, The First Affiliated Hospital, Sun Yat-Sen University, \\ Guangzhou, China
}

\section{Key Words}

Apoptosis $\cdot$ ARDS $•$ Ghrelin $\bullet$ Lipopolysaccharide $・$ Nitric oxide $\bullet$ S-nitrosylation

\begin{abstract}
Background/Aims: In the process of abnormal apoptosis of pulmonary alveolar type II epithelial A549 cells in acute respiratory distress syndrome (ARDS), inducible nitric oxide synthase (iNOS) activity in the lung, nitric oxide (NO) production, and the level of protein $\mathrm{S}$-nitrosylation were increased. However, the role of excessive NO production in sepsis-induced ARDS is controversial. Additionally, ghrelin is a growth hormone that exerts an inhibitory role in cell apoptosis. We examined the effect of $\mathrm{NO}$ and S-nitrosylation on apoptosis of A549 cells induced by Lipopolysaccharide (LPS) and molecular mechanism underlying the anti-apoptotic effect of ghrelin in this process. Methods: Flow cytometry and qPCR were used to detect lentiviral infection efficiency and iNOS gene level, respectively. Extracellular and intracellular NO levels were observed by Griess assay kit and DAF-FM DA. Mitochondrial transmembrane potential, apoptosis rate and SNO levels were determined by flow cytometry, Biotin-Switch method and immunofluoresence staining. The expression of iNOS, apoptotic proteins and JNK were assessed by immunoblot analysis. Results: The results showed about two times increase in iNOS expression and intracellular NO levels response to LPS exposure at 24 hours $(P<0.05)$, while not in extracellular NO levels. NO donors, S-nitroso-N-acetylpenicillamine (SNAP) significantly raised $(36.7 \%, \mathrm{P}<0.05 ; 38.4 \%, \mathrm{P}<0.05 ; 41.8 \%, \mathrm{P}<0.05)$ extracellular NO levels without influencing the intracellular NO levels. LPS increased the apoptosis rate $(42.4 \% \pm 2.6 \%$ vs $2.8 \% \pm 1 \%, \mathrm{P}<0.05)$ of $\mathrm{A} 549$ accompanied by increased Bax levels and decreased $\mathrm{Bcl}-2$ levels through activating JNK signaling, which was reversed when we diminished the iNOS expression in A549 cells using lentiviral vectors encoding iNOS shRNA in the presence of LPS $(24.8 \% \pm 3.8 \%$ vs $42.4 \% \pm 2.6 \%, \mathrm{P}<0.05)$. However, the apoptosis rate was increased when

M. Zeng and C. Huang contributed equally to this work.

\begin{tabular}{ll}
\hline Dr. Mian Zeng, Professor & Department of Medical Intensive Care Unit, First Affiliated Hospital, Sun Yat-sen University \\
and Dr. Yubin Deng, & Guangzhou 510080 (China) \\
Professor & Tel. 13688899950, Fax +86-020-87333122, E-Mail zengmian2004@163.com; dengyub@mail.sysu.edu.cn
\end{tabular}
\end{abstract}


SNAP was added $(38.8 \% \pm 1.3 \%$ vs $24.8 \% \pm 3.8 \%, P<0.05)$. Furthermore, we investigated whether ghrelin exert a protective role against LPS-induced apoptosis and the potential mechanism involved in. Ghrelin alone appeared to decrease iNOS expression $(32.3 \%, \mathrm{P}<0.05$; $42.3 \%, \mathrm{P}<0.05)$, which showed no significant difference between LPS + ghrelin group and LPS group. However, this study showed that ghrelin decreased the intracellular NO production $(38.9 \%, \mathrm{P}<0.05)$, protein $\mathrm{S}$-nitrosylation levels $(33.5 \%, \mathrm{P}<0.05)$, Bax protein expression $(70.2 \%$, $\mathrm{P}<0.05)$, whereas increasing $\mathrm{BCl}-2$ protein expression $(14.1 \%, \mathrm{P}<0.05)$ and mitochondrial transmembrane potential $(\Delta \Psi \mathrm{M})(20.7 \%, \mathrm{P}<0.05)$ in the presence of LPS. Conclusion: The data suggested that NO derived from iNOS induced by LPS stimulation exerts an important role in promoting apoptosis of A549 cells, and ghrelin abolished intracellular NO production and protein S-nitrosylation levels, abrogating the apoptosis of A549 cells partly through inhibiting mitochondrial-dependent pathways.

(C) 2018 The Author(s)

Published by S. Karger AG, Basel

\section{Introduction}

It was admitted early that $\mathrm{NO}$ is generated from L-arginine and oxygen by NO synthases. There are two constitutively expressed NOS isozymes, endothelial (eNOS) and neuronal NOS (nNOS), both of which are Ca2+-responsive and control basal NO levels, and one Ca2+insensitive inducible NOS isozyme (iNOS) which is expressed in response to specific cytokines or bacterial products in mammals [1]. NO possessed a critical role in regulating amounts of physiological and pathophysiological processes including inflammatory responses, blood flow, vascular integrity, cell death, and so on [2]. Macrophages produces NO in the presence of pro-inflammatory stimulation (either directly or indirectly through various NOS), which can induce apoptosis in not only pathogens invading the body, but also in epithelial and endothelial cells. In addition, data obtained from several reports support the direct effects of NO production in driving apoptotic death of cells [3-5].

Both physiological and pathophysiological production of NO triggers many signaling pathways via $S$-nitrosylation of specific protein thiols. The term, S-nitrosylation, refers to the coupling of a NO moiety to the thiol group of reactive cysteine residues and forms an S-nitrosothiol (SNO) [6, 7]. More than a thousand S-nitrosylated (SNO-) proteins were found to be able to regulate functions and activities of many proteins in vivo and in vitro, and NO-mediated S-nitrosylation has been demonstrated to be involved in the apoptosis of pulmonary cells, airway hyper responsiveness, increased pulmonary artery pressure, inflammation, immune suppression and other pathological and physiological processes [8].

Acute respiratory distress syndrome (ARDS) is a frequent complication of sepsis, characterized by the fulminant inflammatory and apoptotic responses that may cause morphological and functional injury to the respiratory membrane [9]. Lipopolysaccharide (LPS), deprived from Gram-negative bacteria, is one of the major causes of septic shock and it can result in the apoptosis of human alveolar epithelial A549 cells [10]. It has been demonstrated that NO is produced at high levels by iNOS during septic and inflammatory conditions [11] and can modulate cell death through S-nitrosylation [1].

Ghrelin is a 28 amino-acid peptide originated from the stomach of rats and humans by Kojima etal.in 1999, initially being responsible for the regulation of growth hormone secretion [12]. A substantial of studies showed that ghrelin exerts a regulatory role in inflammation, apoptosis, cell proliferation, vascular permeability, innate immunity and acquired immunity [13]. Both exogenous ghrelin and increased secretion of ghrelin response to stimulation can reduce the apoptosis of alveolar epithelial cells, inflammatory cell infiltration, reducing the severity of acute lung injury and the mortality of septic rats $[14,15]$. However, the molecular mechanisms underlying the protective effects of ghrelin in sepsis-induced acute lung injury remain poorly understood.

We therefore tested the hypothesis that iNOS derived-NO mediates apoptosis induced by LPS via protein S-nitrosylation and analyze the effect of ghrelin on LPS-induced apoptosis. 


\section{Cellular Physiology Cell Physiol Biochem 2018;49:1840-1855 \begin{tabular}{ll|l} 
and Biochemistry Published online: 20 September, 2018 & $\begin{array}{l}\text { (c) } 2018 \text { The Author(s). Published by S. Karger AG, Basel } \\
\text { www.karger.com/cpb }\end{array}$ \\
\hline
\end{tabular} \\ Zeng et al.: NO Promotes Cell Apoptosis}

\section{Materials and Methods}

\section{Reagents}

The following primary antibodies were used: anti-GAPDH, anti-JNK, anti-p-JNK, anti-Bax, anti-Bcl-2 were purchased from Cell Signaling Technology (Boston, MA, USA), anti-human iNOS antibody from Santa Cruz Biotechnology (Santa Cruz, CA, USA). SYBR® Premix Ex-Taq ${ }^{\mathrm{TM}}$ Kit, DNA Eraser Kit, M-MLV RTase cDNA Synthesis Kit were purchased from TaKaRa (TaKaRa Biotechnology Co., Dalian, China). Alexa Fluor 594-conjugated goat anti-rabbit IgG were from Invitrogen (Invitrogen, Milan, Italy). Annexin V-APC and 7-AAD were purchased from BD Biosciences. Mitochondrial Membrane Potential Detection kit, Griess assay kit and 3-Amino, 4-aminomethyl-2', 7'-difluoresceindiacetate (DAF-FM DA) was from Beyotime Biotechnology (Shanghai, China). S-nitrosylated Protein Detection Kit was purchased from Cayman Chemicals (Ann Arbor, MI, USA), 4',6-diamidino-2-phenylindole dihydrocholride hydrate (DAPI), LPS (Escherichia coli 0127:B8) and other chemicals used in our experiments were all acquired from Sigma (Sigma, St.Louis, MO) unless indicated otherwise.

\section{Lentiviral vectors preparation}

Small hairpin RNA (shRNA) of human iNOS lentivirus gene transfer vector encoding green fluorescent protein (GFP) sequence was constructed by Genechem Co., Ltd, Shanghai, China, to knock down the protein expression of iNOS in A549 cells. The targeting sequence of the shRNA was 5'-AGCGGTAACAAAGGAGATA-3' (GenBank gi: NM_000625), and confirmed by sequencing. Negative control shRNA was designed with the sequence as followed: 5'-TTCTCCGAACGTGTCACGT-3'. The final lentiviral vector titers were contained $8 \times 10^{8}$ $\mathrm{Tu} / \mathrm{mL}$.

\section{Cell culture}

A549 cells were obtained from ATCC. Cells were cultured in DMEM and supplemented with 10\% FBS, $20 \mathrm{mM}$ HEPES, $100 \mathrm{U} / \mathrm{mL}$ penicillin and $100 \mathrm{mg} / \mathrm{mL}$ streptomycin. Cells were maintained in a humidified, $95 \%$ air, $5 \% \mathrm{CO}_{2}$ atmosphere at $37^{\circ} \mathrm{C}$.

\section{Lentiviral infection}

Cells were plated onto 6-well plates at 30\% density. The next day, cells were transduced and cultured with lentiviral vectors encoding iNOS shRNA dissolved in DMEM free of serum for 12 hours, at a range of multiplicity of infection (MOI) $(0,1,10,20$ or 50). The medium was changed after 12 hours, and cells were collected after an additional 48 hours. Since a GFP gene tag was encoded in the lentiviral vector sequence, we used flow cytometry to detect lentiviral infection efficiency. Cells treated by lentiviral vectors encoding iNOS shRNA were collected and washed in ice-cold $1 \times$ PBS twice. After two washes, A549 cells were suspended to $400 \mu \mathrm{L}$ PBS and analyzed using flow cytometry (Beckman, Germany). Furthermore, the knockdown of iNOS expression was confirmed by immunoblot analysis and immunofluorescence staining and qPCR.

\section{Western Blot}

Proteins were extracted using RIPA lysis buffer and protein content was quantified. Samples (30 $\mu \mathrm{g}$ equal protein) were subjected to SDS-PAGE and transferred to a PVDF membrane. The blots were probed with primary antibodies against p-JNK (1:1000), JNK (1:1000), iNOS (1:200), Bax (1:1000) and Bcl-2 (1:1000), subsequently incubated with horseradish peroxidase (HRP) conjugated anti-rabbit secondary antibodies (1:2000). The proteins were visualized using ImageQuant LAS 4000mini. The blots were also probed with rabbit monoclonal anti-GAPDH (1:1000) as a loading control.

\section{Immunofluoresence staining}

A549 cells were fixed in $4 \%$ paraformaldehyde for 20 minutes and then permeabilized with $3 \%$ TritonX-100 in $1 \times$ PBS for 10 minutes. Nonspecific immunoglobulin binding was blocked by incubation with $5 \%$ normal goat serum in PBS for 45 minutes at room temperature. Primary antibody against iNOS (1:200) were diluted in PBS with 5\% goat serum and incubated at $4{ }^{\circ} \mathrm{C}$ overnight. The samples were washed and then incubated in Alexa Fluor 594 anti-rabbit secondary antibody in PBS with 5\% goat serum for 1 hour at room temperature. Cell nuclei were stained with Hochest or DAPI in PBS for 5 minutes. Fluorescence images were obtained using Axio Imager Z1 microscope.

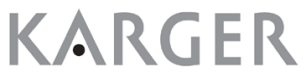




\section{Cellular Physiology Cell Physiol Biochem 2018;49:1840-1855 \begin{tabular}{ll|l} 
and Biochemistry Published online: 20 September, 2018 & $\begin{array}{l}\text { C } 2018 \text { The Author(s). Published by S. Karger AG, Basel } \\
\text { www.karger.com/cpb }\end{array}$ \\
\hline
\end{tabular} \\ Zeng et al.: NO Promotes Cell Apoptosis}

\section{qPCR analysis of transduced A549 cells}

Total RNA was isolated by Trizol and treated with RNase-free DNase using a DNA Eraser Kit to remove residual DNA. Using cDNAs synthesized from the RNAs using an M-MLV RTase cDNA Synthesis Kit as the templates, iNOS mRNA was assessed by real-time fluorescence quantitative PCR (qPCR) according to a SYBR $($ ) Premix Ex-Taq ${ }^{\mathrm{TM}}$ Kit. Forward and reverse primers for PCR amplification were 5'-GCAGCAGCGGCTTCACA-3' and 5'-ACATCCAAACAGGAGCGTCAT-3' for iNOS, respectively, 5'-ACCACAGTCCATGCCATCAC-3' and 5'-TCCACCACCCTGTTGCTGTA-3' for GAPDH, respectively. Values are expressed as relative expression with respect to the endogenous control genes, GAPDH.

The Ct data were imported into Microsoft Excel. The average Ct was calculated for both iNOS and $\mathrm{GAPDH}, \Delta \mathrm{Ct}\left(\mathrm{Ct}_{\mathrm{inOs}}-\mathrm{Ct}_{\mathrm{GAPDH}}\right)$ was determined in three groups, respectively. The mean fold change in expression of the iNOS gene was calculated using the $2^{-\Delta \Delta \mathrm{Ct}}$ method [16], where $\Delta \Delta \mathrm{Ct}=\left(\mathrm{Ct}_{\mathrm{inOS}}-\mathrm{Ct}_{\mathrm{GAPDH}_{\mathrm{G}}}\right)_{\text {shRNA }}$ group $-\left(\mathrm{Ct}_{\text {iNOS }}-\mathrm{Ct}_{\mathrm{GAPDH}}\right)_{\mathrm{CON}}$.

Detection of NO production by flow cytometry

Intracellular NO production was detected by fluorescent probe 3-Amino, 4-aminomethyl-2', 7'-difluoresceindiacetate (DAF-FM DA). After different treatments, the cells were incubated with $5 \mu \mathrm{M}$ DAF-FM DA for $30 \mathrm{~min}$ at $37{ }^{\circ} \mathrm{C}$ in dark followed by three washes with $1 \times \mathrm{PBS}$, then flow cytometry was performed in one hour to measure the fluorescence of NO, which was expressed as histograms of cell green fluorescence.

\section{Measurement of extracellular NO production}

Extracellular NO levels were calculated by the determination of total nitrite + nitrate concentration in the culture medium using a Griess assay kit according to the manufacturer's instructions. Briefly, A549 cells $\left(5.0 \times 10^{5}\right.$ cells $\left./ \mathrm{mL}\right)$ were seeded in 6-well plates and incubated overnight. After different treatments, the culture medium was collected. Equal volumes $(50 \mu \mathrm{L})$ of cell culture supernatant and Griess reagent (1:1 mixture of $1 \%$ sulfanilamide in $5 \%$ phosphoricacid and $0.1 \% \mathrm{~N}$-(1-naphthyl) ethylenediamidedihydrocholide) were mixed and incubated at room temperature for 15 minutes. Absorbance was determined at $540 \mathrm{~nm}$. The concentration of total nitrite + nitrate was calculated according to a standard curve of known nitrite concentrations.

\section{Annexin V-APC/7-AAD Apoptosis Assay}

Cell apoptosis was detected using the Annexin V-allophycocyanin (APC)/7-amino-actinomycin D (7AAD) Apoptosis Detection Kit according to the manufacturer's protocols. Cells were harvested, washed twice in ice-cold $1 \times \mathrm{PBS}$, and then resuspended in $500 \mu \mathrm{L}$ of binding buffer. Cells were incubated in $5 \mu \mathrm{L}$ of Annexin V-APC and $5 \mu \mathrm{L}$ of 7-AAD solution for 15 minutes at room temperature in the dark, and fluorescence levels were measured by flow cytometry (Beckman Coulter).

\section{S-nitrosylation detection}

S-nitrosylation was detected according to the manufacturer's specification of S-nitrosylated Protein Detection Assay Kit based on the modification of biotin-switch method [17, 18]. Briefly, cell-free extract was blocked with buffer A containing blocking reagent. Then S-nitrosothiols in samples were reduced to yield free thiol(s), and subsequently covalently labeled with maleimide-biotin by buffer B containing reducing and labeling reagents in the dark. After the quantification of protein concentration, western blot analyses was performed using S-nitrosylation detection reagent I (HRP; supplied with the kit).

Alternatively, this assay was performed to observe the intensity of S-nitrosylation in the studied cells by Immunofluorescence staining. Briefly, cells were fixed by 4\% paraformaldehyde for 20 minutes, then incubated with buffer B containing blocking reagent and $0.1 \%$ Triton X-100 at $4{ }^{\circ} \mathrm{C}$ for 30 minutes, later with buffer B containing $0.1 \%$ Triton X-100, reducing an labeling reagents for $1 \mathrm{~h}$ at room temperature. Finally, cells were incubated with buffer B containing detection reagent II (Fluorescein) for $1 \mathrm{~h}$, while nuclei were stained with DAPI. Microscopic examination was performed on Axio Imager Z1 microscope. 


\section{Cellular Physiology Cell Physiol Biochem 2018;49:1840-1855

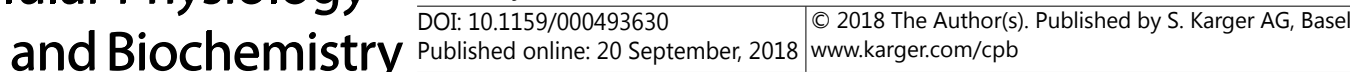 \\ Zeng et al.: NO Promotes Cell Apoptosis}

Assessment of mitochondrial transmembrane potential ( $\triangle \Psi M)$

The $\Delta \Psi \mathrm{M}$ was monitored with the JC-1 reagent in the Mitochondrial Membrane Potential Detection kit according to the manufacturer's instructions. Normally, this dye aggregates in mitochondria with higher mitochondrial membrane potential, emitting red fluorescence at $590 \mathrm{~nm}$ (FL-2), however, depolarized cells in the early stages of cell death as a result of mitochondrial damage possessed decreased mitochondrial transmembrane potential, resulting in JC-1 monomers with green fluorescence at $535 \mathrm{~nm}$ emissions (FL-1). Therefore, the changes of mitochondrial membrane potential $(\Delta \Psi \mathrm{m})$ could be presented as the ratio of the red signal to the green.

After the treatments, cells were washed twice, transferred to a $1.5 \mathrm{~mL}$ microcentrifuge tubes, and then incubated with $1 \times \mathrm{JC}-1$ reagent solution at $37^{\circ} \mathrm{C}$ for $20 \mathrm{~min}$ in the dark. The cells were washed twice with $1 \times$ PBS and then immediately analyzed using a flow cytometer.

\section{Statistical Analysis}

Each experiment was repeated three with good agreement found between the results of individual experiments. The data are expressed as mean \pm SD. Significance was determined using ANOVA followed by LSD-t-test (SPSS 17.0 software.). The differences were considered significant at $\mathrm{P}<0.05$.

Fig. 1. LPS induced the iNOS protein expression and NO production in A549 cells. A, A549 cells were stimulated with LPS for $0,8,12,24$ hours, and iNOS expression was determined by immunoblot. The intensities of iNOS were normalized to that of GAPDH. B, After A549 cells were stimulated with LPS for the indicated time points, the cells were collected for the detection intracellular NO production, using a NO-specific fluorescent probe (DAF-FM DA). C, A549 cells were stimulated with LPS for $0,8,12,24$ hours, and cell culture supernatant was collected to evaluate extracellular NO production by quantifying nitrite accumulation using a Griess assay kit. Results are representative of three independent experiments, mean $\pm \mathrm{SD},{ }^{*} \mathrm{P}<0.05$ vs control.

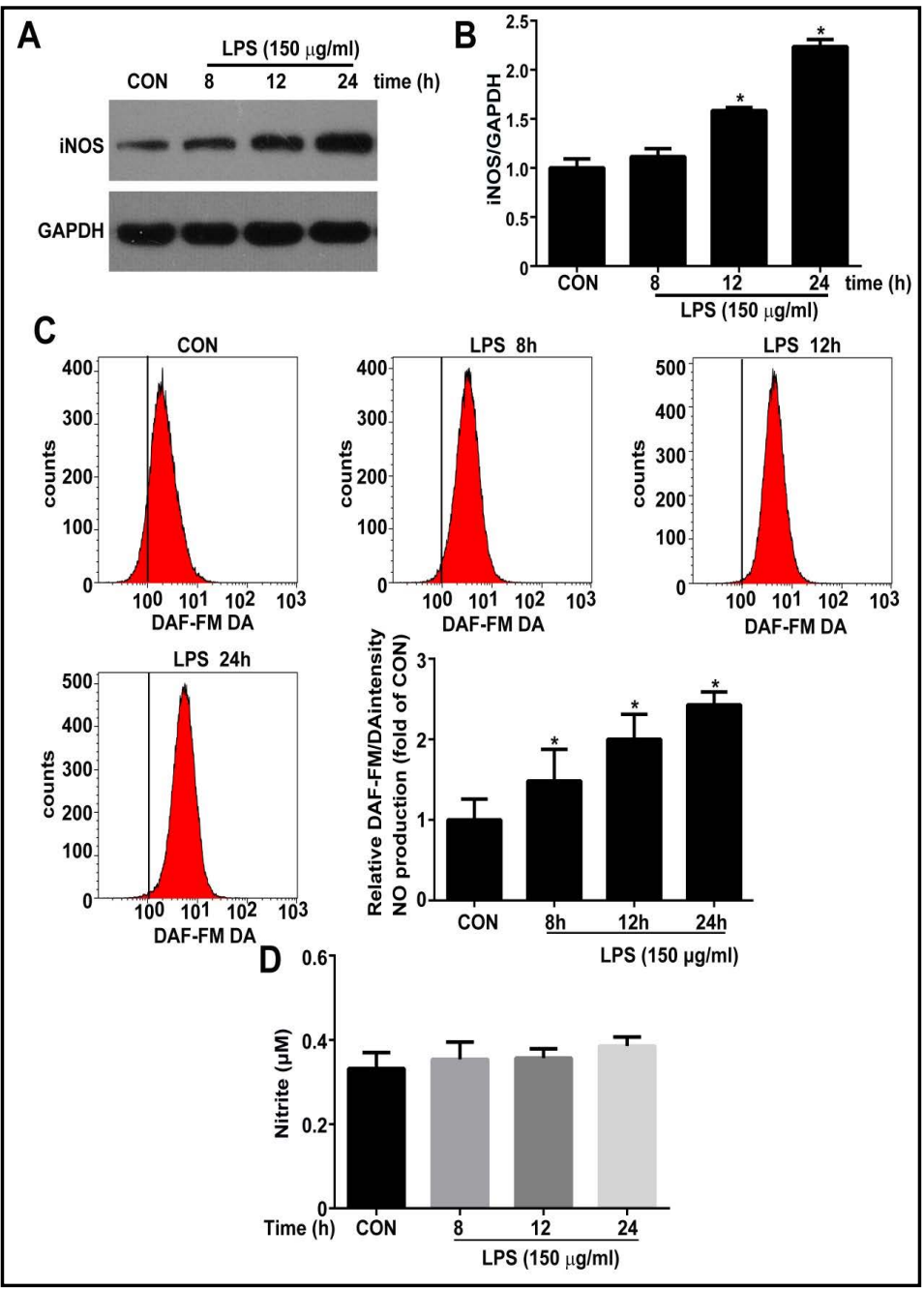




\section{Results}

The effect of LPS on the iNOS protein expression and NO production in A549 cells

First, A549 cells were treated with $150 \mu \mathrm{g} / \mathrm{mL}$ LPS, which has been documented in our previous study [19], for $0,8,12,24$ hours. In this study, LPS caused a marked increase in iNOS protein expression compared to untreated cells in time dependent manner (Fig. 1A, B). iNOS could promote the NO production, so we further investigated the intracellular NO production and extracellular NO levels in A549 cell using NO specific probe DAF-FM DA and Griess agent. LPS also induced the production of intracellular NO in the A549 cells in line with iNOS expression (Fig. 1C), without an increase in nitrite levels or extracellular NO production in the culture medium (Fig. 1D). Intracellular NO levels were significantly increased at 8 hours after stimulation and continued to increase thereafter.

The effect of NO donor (SNAP) on the NO production in A549 cells

Next, we treated A549 cells with a NO donor, S-nitroso-N-acetylpenicillamine (SNAP), and determined the intracellular NO production and extracellular NO levels by the determination of DAF fluorescence intensity and the nitrite concentration in culture medium through NO specific probe DAF-FM DA and Griess agent at the indicated time. Treatment with different periods $(0,8,12,24 \mathrm{~h})$ of SNAP with $200 \mu \mathrm{M}$ on A549 cells resulted in a marked increase in the level of nitrite in the culture medium following treatment while not the DAF fluorescence intensity, indicating that SNAP mainly led to robust increase of extracellular NO production (Fig. 2).

Fig. 2. SNAP induced the extracellular NO production. After A549 cells were stimulated with SNAP for 0,8 , 12,24 hours, and cells was collected for the detection of intracellular and extracellular NO production using a NO-specific fluorescent probe (DAF-FM DA) (A) and Griess assay kit (B). Results are representative of three independent experiments, mean \pm $\mathrm{SD},{ }^{*} \mathrm{P}<0.05$ vs control.

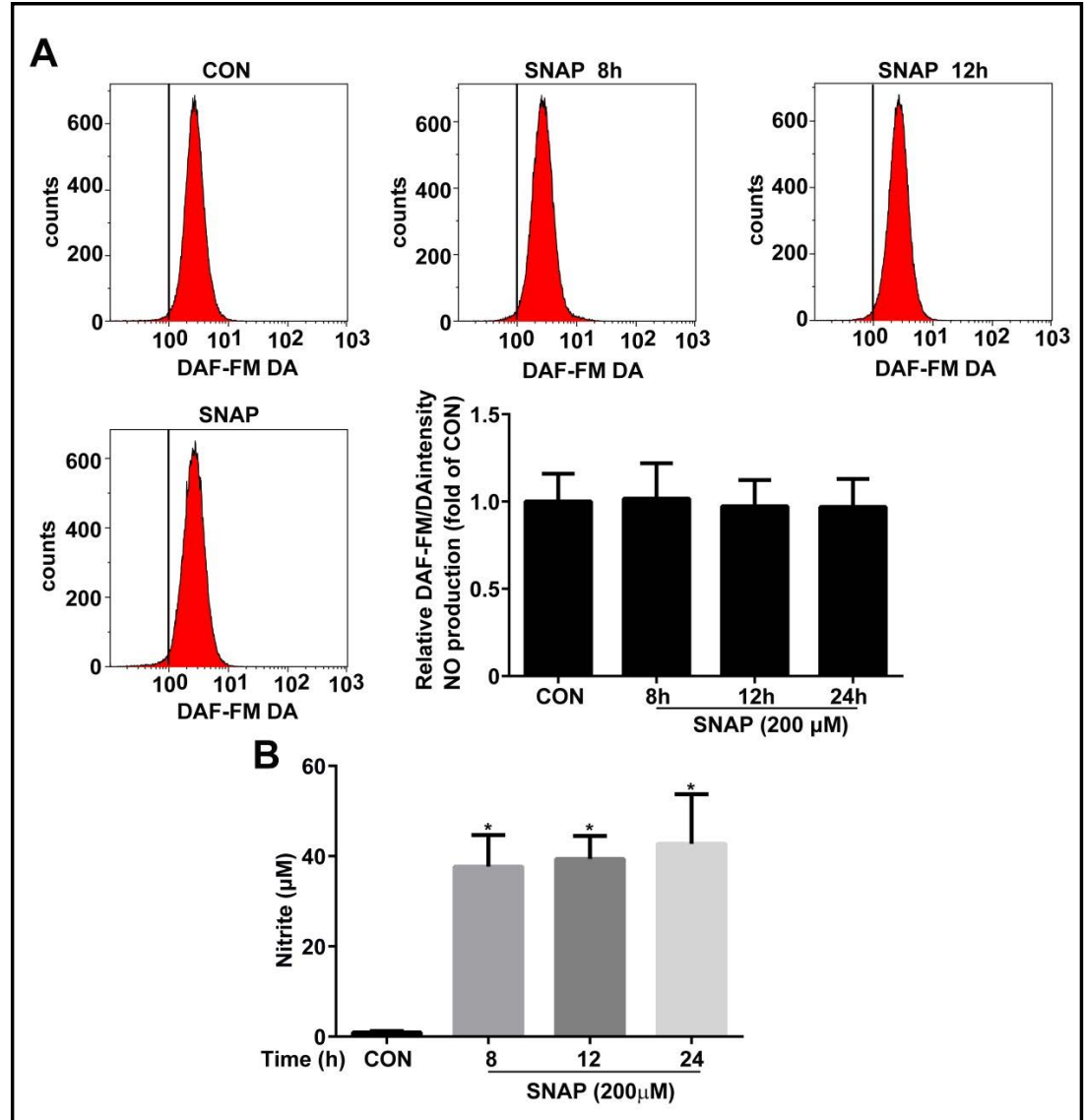


Fig. 3. Lentiviral vector mediated the transfer of iNOS shRNA into A549 cell line. A, Cells were left uninfected or were infected with lentiviral vectors encoding iNOS shRNA at a MOI of 0 , $1,10,20,50$. At 72 hours after infection, GFP expression was analyzed by flow cytometry. Numbers indicate the percentage of $\mathrm{GFP}^{+}$cells. B, Immunofluorescence staining was used to confirm whether lentiviral vectors have effect on expression of iNOS. Cells were fixed and stained with iNOS (red), while nuclei counterstained a dim grey-blue by Hochest (blue). (original imagination, 200x). C, mRNA level of iNOS was detected by qPCR analysis.
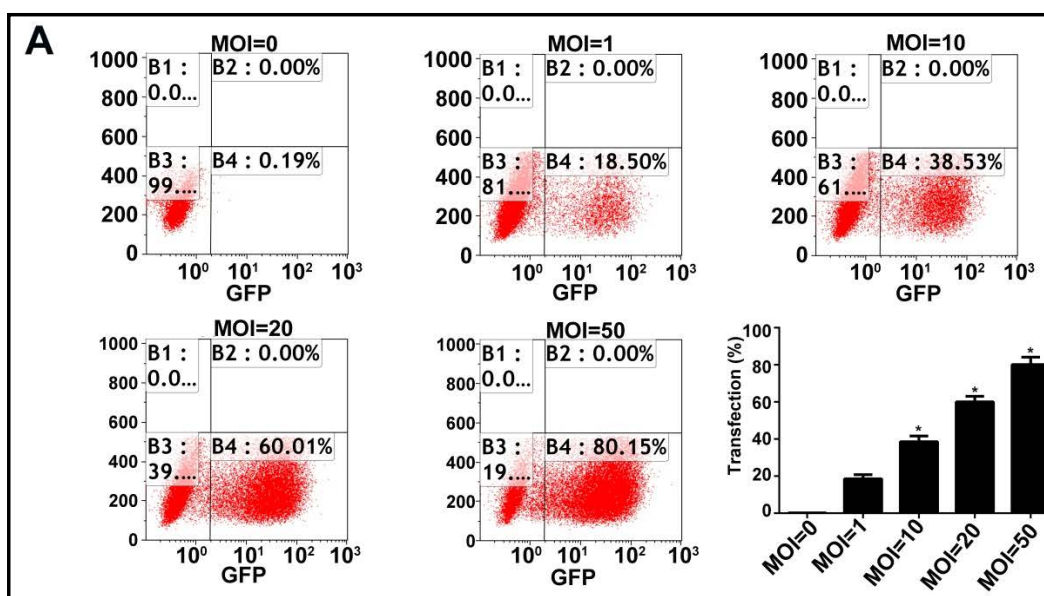

B Hochest GFP
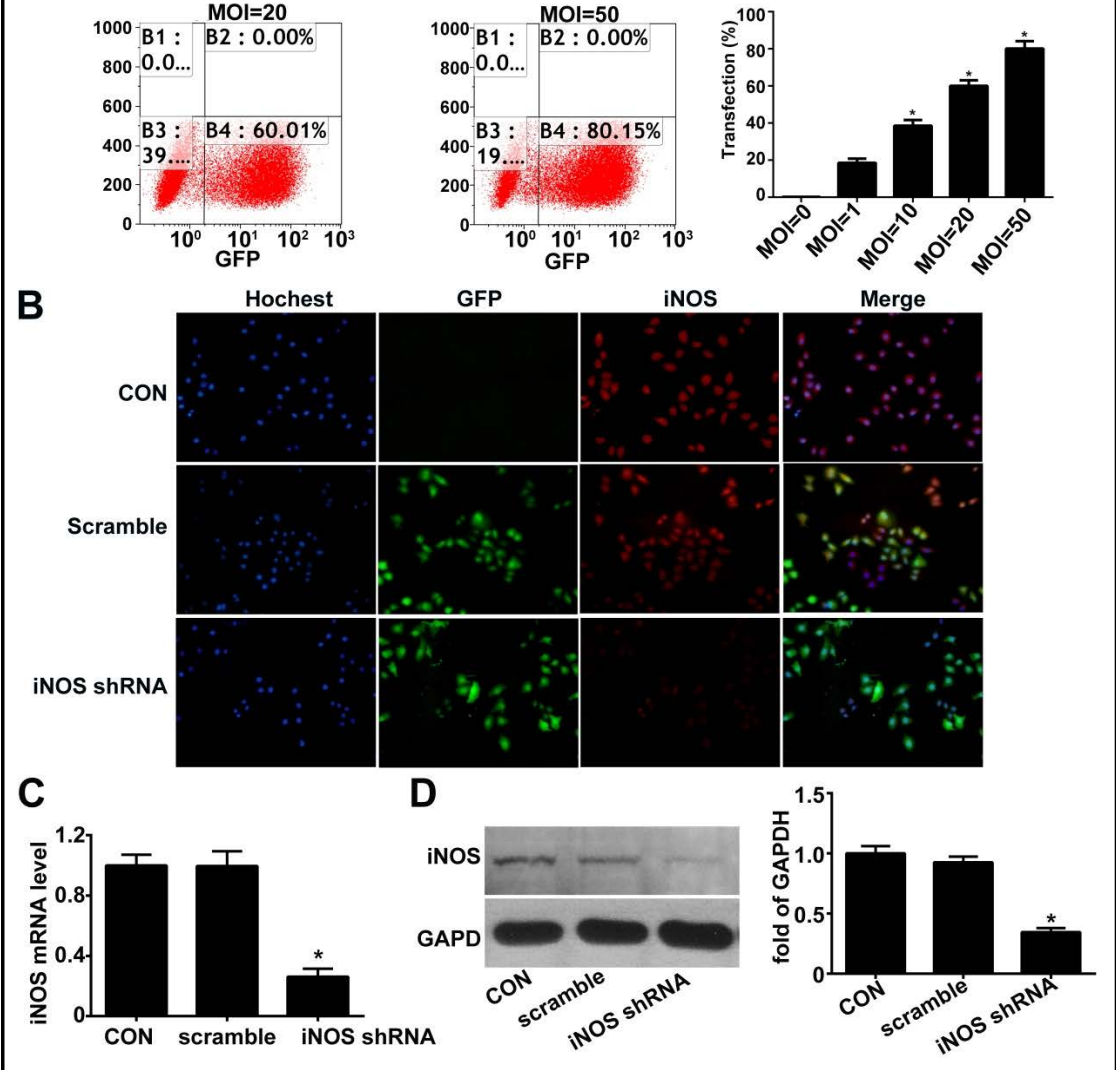

D, iNOS protein expression was evaluated by western blot. Data representative of three independent experiments are shown, mean $\pm \mathrm{SD},{ }^{*} \mathrm{P}<0.05$ vs control.

Long-term gene knockdown in A549 cell line transduced with lentiviral vector encoding iNOS ShRNA

A549 cells were exposed to supernatant containing lentiviral particles of GFP expressing iNOS shRNA lentiviral vectors at different viral concentrations (MOI of $0,1,10,20$ and 50). Transduction of GFP expressing lentiviral vectors in A549 cells was detected by flow cytometry after 72 hours. Efficiency of lentiviral transfection is the efficiency of lentiviral vector entry into epithelial cells. It was estimated with green fluorescence intensity under the fluorescent microscope. As shown in Fig. 3A, the transduction efficiency increased from MOI 1 to MOI 50 and the optimal transduction rate more than $80 \%$ was observed with an MOI of 50 . We proceeded to use a MOI of 50 as the optimal condition for the lentiviral-mediated transduction of iNOS shRNA into A549 cells.

Furthermore, we also subjected the lentiviral vector-treated cells to immunofluorescence staining, qPCR and western blot to detect mRNA level and protein expression of iNOS to verify whether the iNOS protein expressions were successfully knocked down. The mRNA level and protein expression of iNOS in the iNOS shRNA group were significantly decreased compared with scramble and control groups (Fig. 3B, C, D). 
The effect of NO on the apoptosis in A549 cells induced by LPS is partly mediated by JNK signaling pathway

To investigate the mechanism by which NO could modulate apoptotic signaling, first we sought to determine whether JNK signaling pathway, an important signaling event for cell proliferation and cell apoptosis, was activated or inactivated following exposure to LPS or NO donors. iNOS shRNA, applied in vitro to diminish iNOS expression to attenuate the intracellular NO production, and SNAP was applied to be an exogenous NO donor, the alteration of phosphorylated JNK (p-JNK) signaling proteins were observed. Fig. 4A showed that LPS promotes JNK phosphorylation that represents the activation, while the effect could be nullified in A549 iNOS shRNA cells treated with LPS, and the addition of SNAP (LPS+ iNOS shRNA+SNAP group) rescued the p-JNK levels. Protein expression of total JNK kept unchanged. These results suggest that NO production could result in the phosphorylation of its downstream proteins and their activation.

Fig. 4. The effect of NO on the apoptosis in A549 cells induced by LPS is partly mediated by JNK signaling pathway. A, A549 cells were treated with or without the presence of LPS, iNOS was inhibited in LPS-treated A549 iNOS shRNA cells. In A549 iNOS shRNA cells, NO was added using the indicated concentrations of SNAP. Then the phosphorylation of JNK expression, were determined by immunoblot after $12 \mathrm{~h}$ treatments. (BC), A549 cells were untreated (Control) or treated for 24 $h$ with LPS, LPS + iNOS shRNA, or LPS + iNOS shRNA+ SNAP, apoptotic proteins ( Bax and Bcl-2) expressions were measured by immunoblot, apoptosis rate was assayed for Annexin V-APC and 7-AAD staining by flow cytometry. Annexin V-APC-/7-AAD- (normal), Annexin V-APC+/7-AAD- (early apoptosis), Annexin $\mathrm{V}-\mathrm{APC}+/ 7-\mathrm{AAD}+$ (late apoptosis). Results are representative of three independent experiments, mean $\pm \mathrm{SD}$, ${ }^{*} \mathrm{P}<0.05$ vs control, \# $\mathrm{P}<0.05$ vs LPS group, ${ }^{*} \mathrm{\# P}<0.05$ vs LPS+iNOS shRNA group.

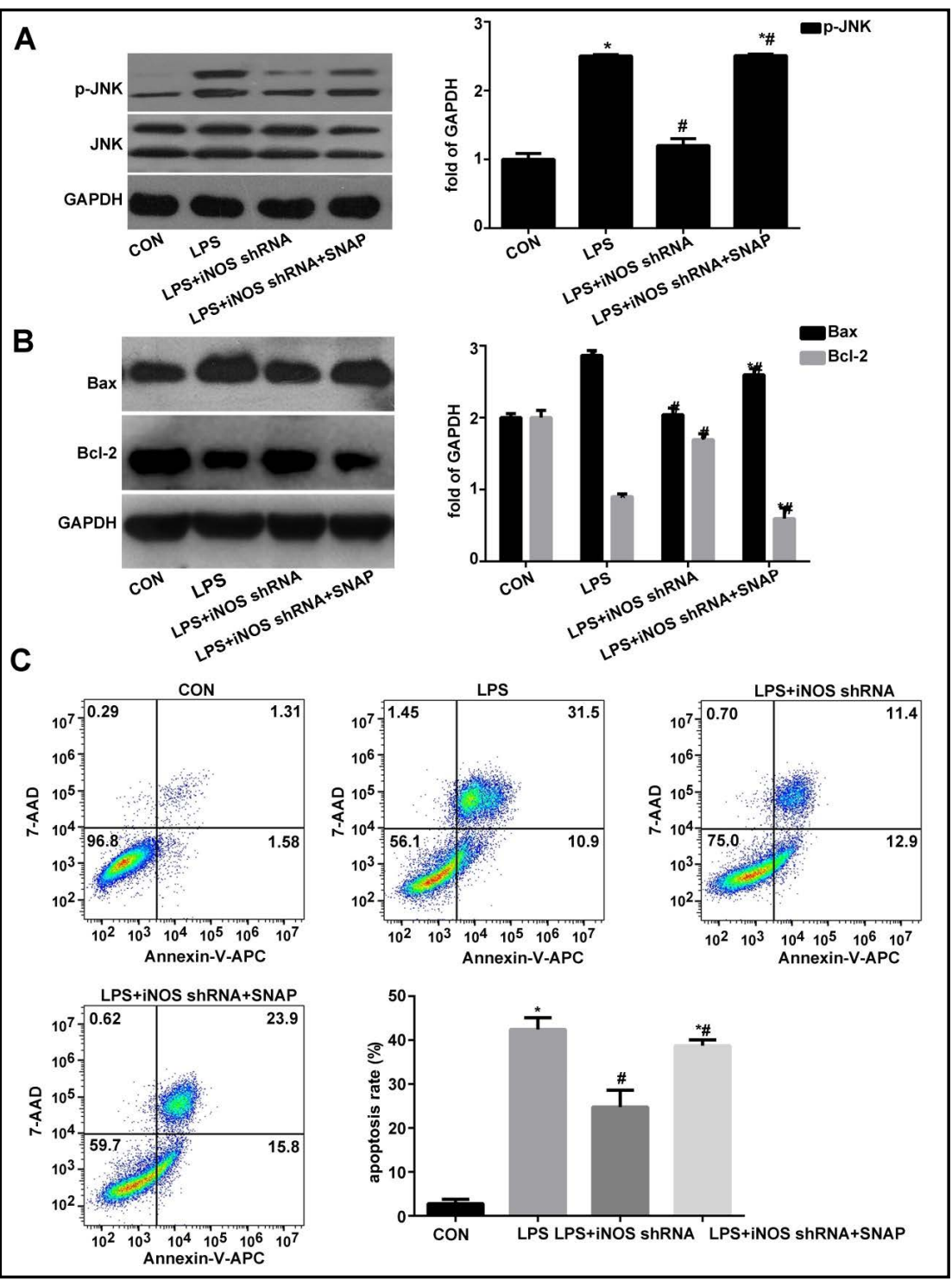


To further demonstrate the role of NO in promoting apoptosis, Annexin V-APC/7-AAD apoptosis assay and immunoblot were applied to detect the apoptosis rate and apoptotic protein expression (Bax, Bcl-2). The expression patterns of apoptotic proteins (Bax, Bcl-2) were first evaluated. LPS elevated Bax protein levels and decreased the protein level of $\mathrm{Bcl}-2$, the expression patterns of $\mathrm{Bax}, \mathrm{Bcl}-2$ were
Fig. 5. The effect of ghrelin on the expression of iNOS in A549 cells. A549 cells were treated with ghrelin at the dosage of $100 \mathrm{nM}, 400 \mathrm{nM}$, with or without the presence of LPS, the iNOS expression was determined by immunoblot after $12 \mathrm{~h}$ treatments. Results are representative of three independent experiments, mean \pm $\mathrm{SD},{ }^{*} \mathrm{P}<.05$ vs control.
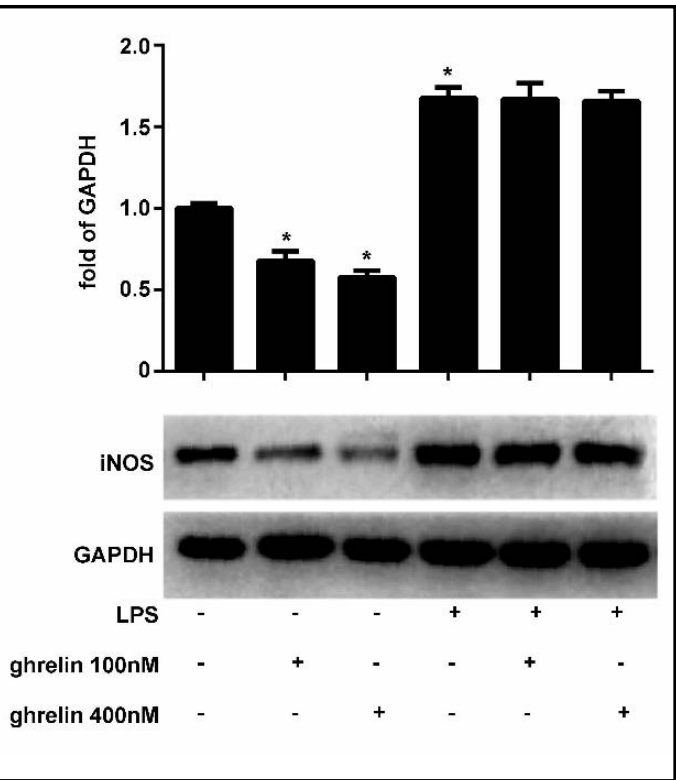

Fig. 6. The effect of ghrelin on intracellular NO production and SNO levels. A549 cells were in the absence (control) or presence of LPS, or cells were pre-incubated with ghrelin (100 nM) for $20 \mathrm{~min}$ prior to the addition of LPS. A, After $12 \mathrm{~h}$, intracellular NO production was evaluated by NOspecific fluorescent probe (DAF-FM DA). (B-C), SNO levels were measured by biotinswitch method and immunofluorescence staining based on biotin-switch method, respectively. Results are representative of three independent experiments, mean \pm $\mathrm{SD},{ }^{*} \mathrm{P}<.05$ vs control, $\# \mathrm{P}<.05$ vs LPS treated alone.

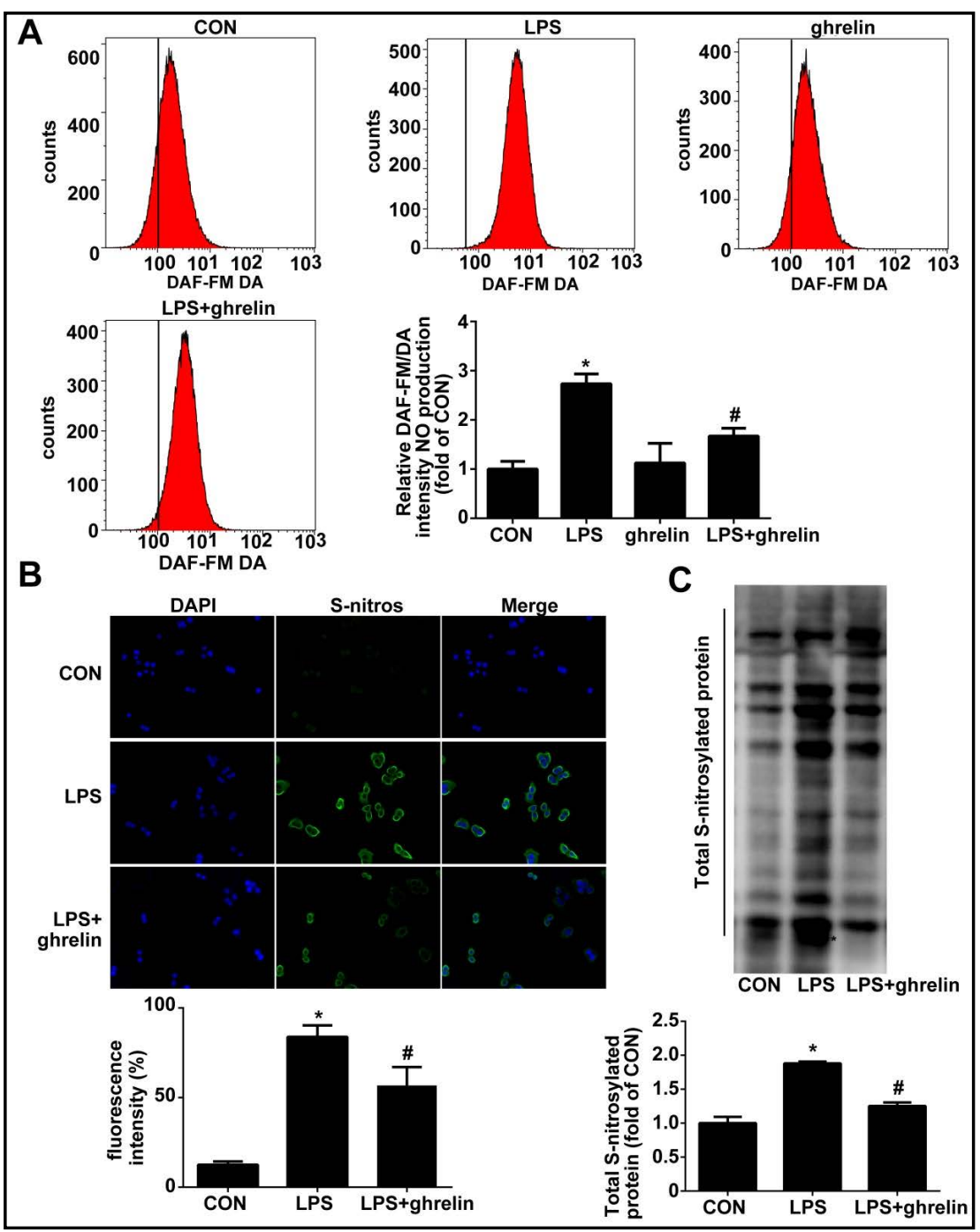


reversed when iNOS expression was interfered in exposure to LPS. However, the Bax and Bcl-2 protein levels were identical to that in LPS stimulation in presence of SNAP (Fig. 4B). Furthermore, LPS stimulation induced a significant increase in the percentage of Annexin $\mathrm{V}-\mathrm{APC}+/ 7-\mathrm{AAD}$ - and Annexin V-APC+/7-AAD+ cells, suggesting an increase in the number of apoptosis cells and apoptosis rate according to the result of flow cytometry analysis (Fig. 4C), which was abrogated by the knockdown of iNOS expression. After the addition of exogenous NO with SNAP, the apoptosis rate of A549 iNOS shRNA cells in the presence of LPS was amplified, indicating an important role for NO in this process. Collectively, both iNOSderived NO and NO from NO donors play critical role in promoting cell apoptosis.

Ghrelin did not appear to reduce the iNOS expression in the exposure of LPS.

Ghrelin alone at $100 \mathrm{nM}$ and $400 \mathrm{nM}$ appeared to decrease the expression of iNOS in comparison to control treatment, however, there was no significant difference of that between LPS+ghrelin groups and LPS groups (Fig. 5), suggesting that ghrelin could not reduce LPS-induced iNOS expression.

Ghrelin exerts protection against LPS-induced apoptosis in A549 cells through reducing the SNO levels.

In this study, we proceeded to use the dosage of $100 \mathrm{nM}$ of ghrelin, documented in our previous research [19]. S-nitrosylation involves the combination of NO moiety with the reactive thiol of an adjacent cysteine residue to form an S -nitrosothiol (SNO) [6]. In our study, intracellular NO production and SNO levels were increased in the LPS group, pretreatment of ghrelin diminished the striking increase of intracellular NO production and SNO levels

Fig. 7. The effect of ghrelin on LPSinduced apoptosis. A, The effect of ghrelin on the changes of mitochondrial $\mathrm{m}$ e $\mathrm{m}$ b $\mathrm{r}$ a $\mathrm{n}$ e potential under LPS stimulation. Cells were either incubated or not incubated with ghrelin before LPS treatment. At the end of the treatment period (24h), changes in mitochondrial membrane potential was monitored by JC-1 staining using flow cytometry, furthermore, the quantity of normal $\Delta \Psi$ m cells relative to the cell total of each
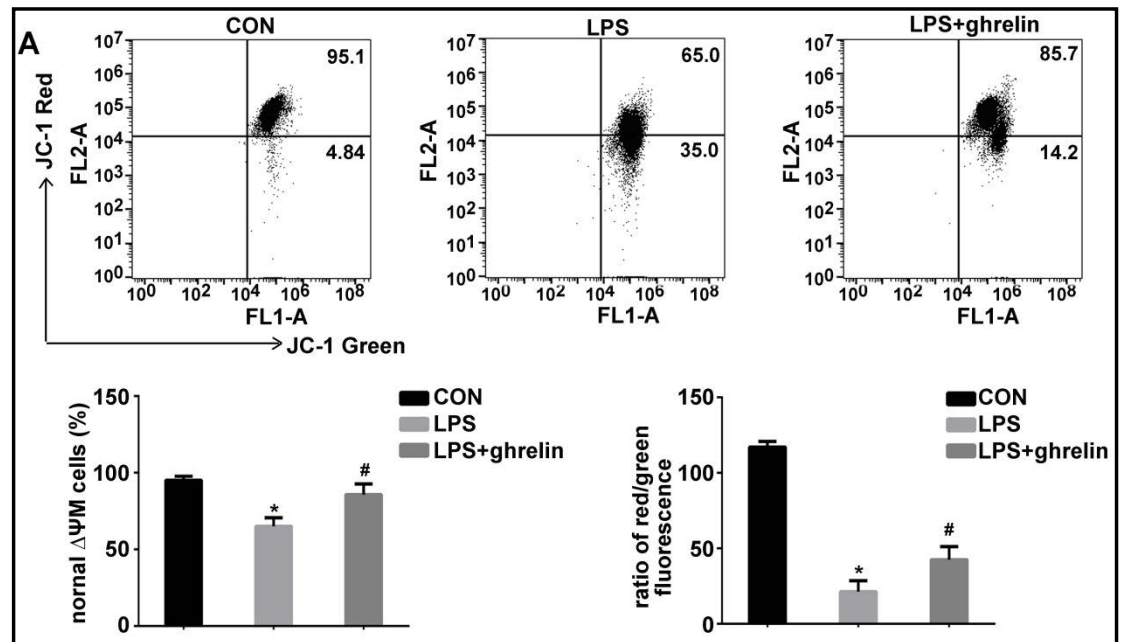

B

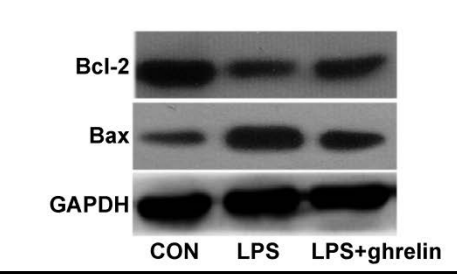
group and ratio of red/green fluorescence were evaluated. B, Western-assisted analysis was applied in A549 cells untreated (Control) or treated for $24 \mathrm{~h}$ with LPS, LPS + ghrelin for Bax, Bcl-2 protein expression, and the relative quantities of Bax, Bcl-2 protein to GAPDH. Results are representative of three independent experiments, mean $\pm \mathrm{SD}, * \mathrm{P}<.05$ vs control, $\# \mathrm{P}<.05$ vs LPS treated alone. 
induced by LPS, as evidenced by NO specific fluorescent probe, biotin-switch method and immunofluorescence staining (Fig. 6A-C).

Ghrelin protects mitochondrial dysfunction-related apoptosis in A549 cells induced by LPS by regulating the expression of $\mathrm{Bcl}-2$ family proteins.

The depletion of $\Delta \Psi \mathrm{m}$ is an indicator of cells undergoing the early phase of mitochondriondependent apoptosis. To investigate whether mitochondrial dysfunction contributes to LPS induced apoptosis in A549 cells, we first examined the change of mitochondrial membrane potential by JC-1 method. JC-1 aggregates in normal cells with higher $\Delta \Psi \mathrm{m}$ emit red fluorescence and JC-1 monomers in apoptotic cells with low $\Delta \Psi \mathrm{m}$ emit green fluorescence. On treatment with LPS, the population of cells with high membrane potential decreased from $95.1 \%$ to $65.0 \%$, but ghrelin pre-incubation raised the ratio to $85.7 \%$. Nonetheless, there was a decrease in the ratio of red/green in cells treated with LPS to the control cells, suggesting the depolarization of mitochondria and reduced $\Delta \Psi \mathrm{m}$, however, the ratio was increased in LPS+ghrelin cells (Fig. 7A), indicating that ghrelin partly recovered the depletion of $\Delta \Psi \mathrm{m}$ induced by LPS.

Moreover, it was observed that ghrelin pretreatment enhanced the expression of anti-apoptotic Bcl-2 with concomitant decreased expression of pro-apoptotic Bax protein compared with LPS stimulation alone (Fig. 7B). These results indicate that ghrelin may rearrange the ratio of Bcl-2 to Bax and therefore may inhibit apoptotic cell death by inactivating the intrinsic signaling pathway.

\section{Discussion}

In the present study, we demonstrated that iNOS-derived NO and NO-mediated S-nitrosylation own a critical role in LPS-induced apoptosis, moreover, ghrelin's resistance of elevated NO production and S-nitrosylation levels and inhibitory role of ghrelin to apoptosis partly due to the intrinsic signaling pathway were also observed.

Some researchers have previously reported that LPS administration could amplify iNOS expression and activity, contributing to a robust NO production and NO-dependent oxidative/ nitrosative stress, which may consequently augment the risk of multi-organ failure and death during sepsis [20]. The role of NO derived from iNOS under pathological conditions, including endotoxemia, sepsis, remains unclear that iNOS inhibitors were suggested to be conducive to liver dysfunction in LPS-treated rats, but did not possess a beneficial role in lightening caused by the endotoxin-caused organ damage, on the other hand [21]. NO is widely distributed in tissues and organs and reported to be involved in various pathophysiological reactions and reacts as a downstream molecular target to regulate apoptosis. However, the relationship between the NO signaling pathway and cell apoptosis in ARDS is still not adequately understood. Therefore, uncovering the molecular mechanism of NO may be an important event in the development of novel preventive treatments.

Excess NO could cause damage to cells or tissues through targeting DNA, mitochondria, cell membranes and proteins [3, 22, 23]. Growing body of evidence indicated that NO and NOS-derived NO production are positively correlated with apoptosis [4]. Xu et al., found that light irradiation could amplify the cancer cell apoptosis by enhancing NO release. Their observations supported the promoting role of NO in cell apoptosis [3]. Shafaroodi et al. have previously reported that $\mathrm{NO}$ augmented cell apoptosis by activated both the death receptor pathway, in which Fas expression was increased to activate caspase and the mitochondrial pathway, Bax/Bcl-2 ratio was subsequently increased [5]. In this study, it has been clarified that LPS induced an increase in iNOS protein expression and NO production, contributing to the enhanced cell apoptosis rate documented by Annexin V-APC/7-AAD apoptosis assay. A549 iNOS shRNA cells are partially protected from LPS-induced apoptosis evidenced by Annexin V-APC/7-AAD apoptosis assay and opposite protein expression of Bax and Bcl-2 were demonstrated compared with LPS treated alone, however the patterns of cell apoptosis 
was augmented by the addition of NO donor (SNAP), which was similar to that of LPS group, compared with A549 iNOS shRNA cells in presence of LPS. The present results confirmed a previous report in which combined stimulation of cytokines and LPS to rat alveolar type II epithelial cells increased iNOS-derived NO generation and apoptosis, furthermore, a decrease in cell apoptosis was demonstrated when an iNOS inhibitor was applied [24].

We further sought to investigate the molecular underpinnings involved in the NOmediated apoptosis pathway. Jun amino-terminal kinase (JNK) is a member of mitogenactivated protein kinases (MAPKs) family, accounting for the development of inflammatory responses and cell apoptosis in various conditions leading to cellular dysfunction and organ failures. Activated JNK can inactivate its downstream Bcl-2 families, causing the release of cytochrome $c$, initiating cell death signaling pathways [25]. Among the MAPK family, JNK and p38 have been suggested to be apoptosis-inducing pathways complicated in NO toxicity $[26,27]$. Chen et al. reported that pathologically blocking JNK activation could reduce NOinduced apoptosis, indicating an important role of JNK in NO-induced apoptosis [27]. In this report, LPS treatment was followed by rapid JNK phosphorylation and a reduction in Bcl-2 expression and increased Bax expression, contributing to cell apoptosis. Conversely, inhibited JNK phosphorylation, increased Bcl-2 expression and decreased Bax expression were detected in A549 iNOS shRNA cells following LPS treatment. Furthermore, the addition of SNAP enhanced cell apoptosis similarly as LPS did. Collectively, our data implied that activation of JNK could play an important role in NO-mediated lethality. Nitrosylation is a reversible post-translational modification in biological reactions downstream of NO signaling $[28,29]$. Combined stimulation of LPS and IFN- $\gamma$ results in induction of iNOS and reactive nitrogen species (RNS) [30], which can nitrosylate cysteine by attaching NO covalently to redox centers to form an S-nitrosothiol (SNO) [6]. NO and it-derived RNS could cause cell cytotoxicity leading to cell apoptosis through targeting functional proteins by S-nitrosylation. S-nitrosothiols (SNOs) play an essential role in the pathogenesis of endotoxic/septic shock [28]. Previous work revealed that increases of SNO levels were required for exogenous NO donor to initiate A549 cells apoptosis [31].

Ghrelin could up-regulate iNOS expression when Sudar et al. reported that iNOS mRNA and protein expression were elected in the heart of ghrelin treated rats [32], and also possessed an inhibited role in other experiment in which Mao et al. reported that ghrelin pretreatment could attenuate LPS- or palmitic acid-induced hepatocyte apoptosis partly through the inhibition of mitogen-activated protein kinases (MAPKs)/iNOS, decreasing iNOS protein expression and mRNA level, levels of NO of cell supernatants [33]. Moreover, our previous study demonstrated that ghrelin could mitigate lung injury in septic ARDS and reduce iNOS protein expression in lung tissues [34]. In present study, pre-treatment with ghrelin did not have a notable influence on the iNOS protein expression in A549 cells induced by LPS, although it alone appeared to decrease the iNOS protein expression. Interestingly, our data showed that ghrelin could inhibit the NO production in A549 cells induced by LPS treatment, which was in contrast to what Yang et al. reported that the NO production is in accordance with the increased plasma ghrelin levels in patients with idiopathic pulmonary arterial hypertension (IPAH) [35]. This contradiction may be attributable to that a small amount of NO could enhance vasodilation and regulate blood pressure [36, 37], but excessive NO production, therefore, exert a harmful role. Besides, ghrelin could exert countering effect of the LPS-induced inflammation consequences derived from $\mathrm{H}$. pylori stimulation by decreasing S-nitrosylation of AKT and increasing in its phosphorylation [38]. In present study, increased levels of SNOs were detected in LPS group as evidenced by Biotin-Switch method and related immunofluorescence, and the partly blockade of this increase was demonstrated in presence of ghrelin pre-incubation.

Nitric oxide could contribute to mitochondrial damage. The disruption of mitochondrial membrane potential is an early but crucial step in the intrinsic pathways of apoptosis characterized by integration of the mitochondrial membranes, correlating with an increased expression of Bax/Bcl-2 ratio, which is followed by cytochrome c release and caspase- 3 activation [39]. It was observed that ghrelin alleviated the decrease of anti-apoptotic Bcl-

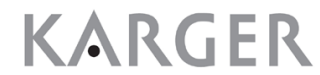




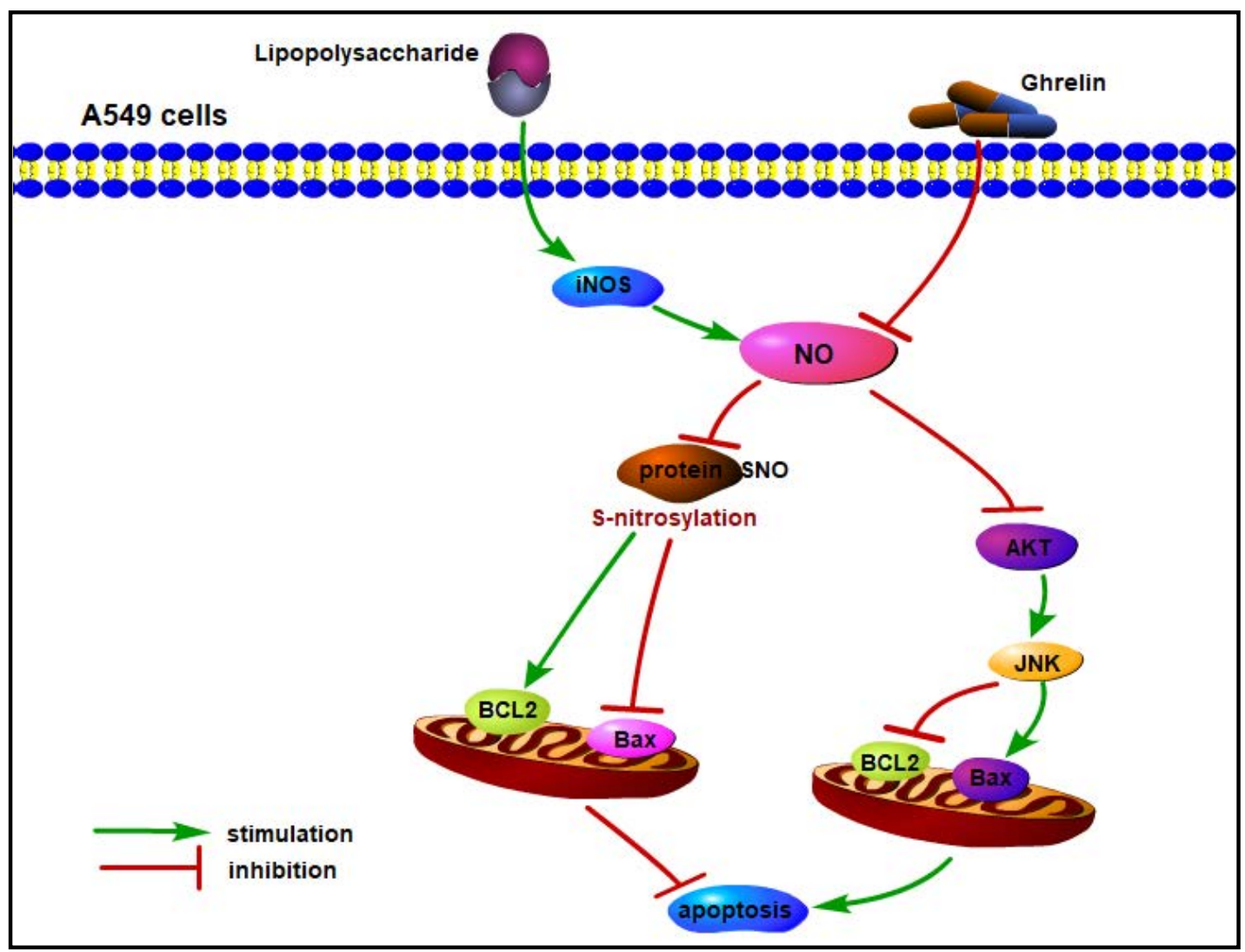

Fig. 8. Schematic illustration showing mechanism of NO action and cytoprotective signaling of ghrelin in LPS-induced apoptosis in alveolar epithelial cells. LPS induced iNOS expression, followed by robust NO production, leading to S-nitrosylation and SNOs formation, inhibiting AKT activation and activating JNK signaling, finally resulting depletion of mitochondrial membrane potential and cell apoptosis. Pretreatment of ghrelin abrogated NO production and SNOs formation, and inhibited apoptotic events by hampering the mitochondrial injury and altered the Bcl-2/Bax expression.

2 expression, increase of pro-apoptotic Bax translocation to mitochondria in the presence of LPS. Current experiments in our lab indicated that LPS caused apoptosis of A549 cells by mitochondrial signaling steps involving the modulation of the function of Bcl-2 family, meanwhile, ghrelin may rearrange the ratio of Bcl-2 to Bax and therefore may inhibited apoptotic cell death by inactivating the intrinsic signaling pathway. Collectively, our results demonstrated that the incubation of ghrelin decreased the NO generation and SNO levels, upregulated the anti-apoptosis protein $\mathrm{Bcl}-2$ expression, downregulated pro-apoptosis protein Bax expression, and inhibited the mitochondria-mediated apoptosis.

\section{Conclusion}

These data indicated that iNOS/NO participates in the apoptosis of alveolar epithelial cells. Ghrelin could protect cell against mitochondrial apoptotic pathway partially through prohibiting NO production and S-nitrosylation (Fig. 8). These results support NO signaling pathway and it-derived S-nitrosylation of proteins as pivotal role in various pathophysiological functions, such as inflammation and apoptosis, thus adding to the overall understanding of the mechanism involved in the occurrence and development of ARDS. However, our studies also have some limitations. This is only an in vitro experiment, the effect of NO and ghrelin should be further tested by animal study. Also, the S-nitrosylation of some specific proteins may be investigated to try to provide potential new therapeutic strategy targeting a specific 


\section{Cellular Physiology Cell Physiol Biochem 2018;49:1840-1855 \begin{tabular}{ll|l} 
and Biochemistry Published online: 20 September, 2018 & $\begin{array}{l}\text { @ 2018 The Author(s). Published by S. Karger AG, Basel } \\
\text { www.karger.com/cpb }\end{array}$ \\
\hline
\end{tabular} \\ Zeng et al.: NO Promotes Cell Apoptosis}

protein. Third, the effect of NO signaling on other patterns of cell death involved in sepsisinduced ARDS, including necrotic apoptosis, pyroptosis, may be further investigated. Finally, the experimental data cannot be directly introduced into the real clinical practice. There is still a long way to go that drugs targeting at S-nitrosylation can be used in ARDS patients.

\section{Abbreviations}

ARDS (Acute respiratory distress syndrome); LPS (Lipopolysaccharide); $\triangle \Psi M$ (Mitochondrial transmembrane potential); NO (nitric oxide); NOS (nitric oxide synthase); SNAP (S-nitroso-N-acetylpenicillamine); SNO (S-nitrosothiol).

\section{Acknowledgements}

This work was supported by Grant 2014A020212151/2016A020216009 from the Science and Technology Planning Project of Guangdong Province of China, Grant 2014Y200136 from the Science and Technology Program of Guangzhou City of China and Grant 81670066 National Natural Science Foundation of China. Disclosure Summary: The authors have nothing to disclose.

Mian Zeng conceived and designed the studies. Chunrong Huang performed the experiments, analyzed the data and drafted the manuscript. Qingui Chen and Haichong Zheng performed some of the experiments. Wanmei He analyzed the data. Yubin Deng revised the article critically for important intellectual content.

\section{Disclosure Statement}

The authors declare no competing financial interests.

\section{References}

1 Iyer AK, Rojanasakul Y, Azad N: Nitrosothiol signaling and protein nitrosation in cell death. Nitric Oxide 2014;42:9-18.

2 Han T, Tang Y, Li J, Xue B, Gong L, Li J, Yu X, Liu C: Nitric oxide donor protects against acetic acid-induced gastric ulcer in rats via S-nitrosylation of TRPV1 on vagus nerve. Sci Rep 2017;7:2063.

-3 Xu J, Zeng F, Wu H, Hu C, Yu C, Wu S: Preparation of a mitochondria-targeted and NO-releasing nanoplatform and its enhanced pro-apoptotic effect on cancer cells. Small 2014;10:3750-3760.

4 Chen JH, Chu YL, Cao JL, Yang ZT, Shi ZL, Guo X, Wang ZL: [Effect of NO and Fas pathway on T-2 induced apoptosis in chondrocytes]. Sichuan Da Xue Xue Bao Yi Xue Ban 2006;37:583-586.

5 Shafaroodi H, Hashemi M, Sharif ZN, Moezi L, Janahmadi Z, Dehpour AR: The Possible Role of Nitric Oxide and Oxidative Stress in the Enhanced Apoptosis of Cardiac Cells in Cirrhotic Rats. Acta Med Iran 2017;55:29-34.

-6 Stamler JS, Lamas S, Fang FC: Nitrosylation. the prototypic redox-based signaling mechanism. Cell 2001;106:675-683.

-7 Ghashghaeinia M, Wesseling MC, Ramos E, Petkova-Kirova P, Waibel S, Lang E, Bissinger R, Alzoubi K, Edelmann B, Hosseinzadeh Z, Dreischer P, Shahvaroughi-Farahani A, Mrowietz U, Koberle M, Kaestner L, Bernhardt I, Martinez-Ruiz A, Wieder T, Lang F: Trifluoperazine-Induced Suicidal Erythrocyte Death and S-Nitrosylation Inhibition, Reversed by the Nitric Oxide Donor Sodium Nitroprusside. Cell Physiol Biochem 2017;42:1985-1998.

8 Gaston B, Singel D, Doctor A, Stamler JS: S-nitrosothiol signaling in respiratory biology. Am J Respir Crit Care Med 2006;173:1186-1193. 


\section{Cellular Physiology Cell Physiol Biochem 2018;49:1840-1855 \begin{tabular}{l|l|l} 
and Biochemistry 10.1159/000493630 & $\begin{array}{l}\text { C) } 2018 \text { The Author(s). Published by S. Karger AG, Basel } \\
\text { www.karger.com/cpb }\end{array}$ \\
\hline
\end{tabular} \\ Zeng et al.: NO Promotes Cell Apoptosis}

9 Matthay MA, Zimmerman GA: Acute lung injury and the acute respiratory distress syndrome: four decades of inquiry into pathogenesis and rational management. Am J Respir Cell Mol Biol 2005;33:319-327.

10 Liu X, Shao K, Sun T: SIRT1 regulates the human alveolar epithelial A549 cell apoptosis induced by Pseudomonas aeruginosa lipopolysaccharide. Cell Physiol Biochem 2013;31:92-101.

-11 Park KS, Guo Z, Shao L, Du Q, Geller DA: A far-upstream Oct-1 motif regulates cytokine-induced transcription of the human inducible nitric oxide synthase gene. J Mol Biol 2009;390:595-603.

12 Kojima M, Hosoda H, Date Y, Nakazato M, Matsuo H, Kangawa K: Ghrelin is a growth-hormone-releasing acylated peptide from stomach. Nature 1999;402:656-660.

-13 Liang QH, Jiang Y, Zhu X, Cui RR, Liu GY, Liu Y, Wu SS, Liao XB, Xie H, Zhou HD, Wu XP, Yuan LQ, Liao EY: Ghrelin attenuates the osteoblastic differentiation of vascular smooth muscle cells through the ERK pathway. PLoS One 2012; 7:e33126.

14 Imazu Y, Yanagi S, Miyoshi K, Tsubouchi H, Yamashita S, Matsumoto N, Ashitani J, Kangawa K, Nakazato M: Ghrelin ameliorates bleomycin-induced acute lung injury by protecting alveolar epithelial cells and suppressing lung inflammation. Eur J Pharmacol 2011;672:153-158.

-15 Tsubouchi H, Yanagi S, Miura A, Iizuka S, Mogami S, Yamada C, Hattori T, Nakazato M: Rikkunshito ameliorates bleomycin-induced acute lung injury in a ghrelin-independent manner. Am J Physiol Lung Cell Mol Physiol 2014;306:L233-245.

16 Livak KJ, Schmittgen TD: Analysis of relative gene expression data using real-time quantitative PCR and the 2(-Delta Delta C(T)) Method. Methods 2001;25:402-408.

$\checkmark 17$ Lee M, Choy JC: Positive feedback regulation of human inducible nitric-oxide synthase expression by Ras protein S-nitrosylation. J Biol Chem 2013;288:15677-15686.

18 Jaffrey SR, Snyder SH: The biotin switch method for the detection of S-nitrosylated proteins. Sci STKE 2001;2001:pl1.

19 Huang C, Zheng H, He W, Lu G, Li X, Deng Y, Zeng M: Ghrelin ameliorates the human alveolar epithelial A549 cell apoptosis induced by lipopolysaccharide. Biochem Biophys Res Commun 2016;474:83-90.

20 Escames G, Lopez LC, Ortiz F, Ros E, Acuna-Castroviejo D: Age-dependent lipopolysaccharide-induced iNOS expression and multiorgan failure in rats: effects of melatonin treatment. Exp Gerontol 2006;41:11651173.

-21 Garcia JA, Ortiz F, Miana J, Doerrier C, Fernandez-Ortiz M, Rusanova I, Escames G, Garcia JJ, AcunaCastroviejo D: Contribution of inducible and neuronal nitric oxide synthases to mitochondrial damage and melatonin rescue in LPS-treated mice. J Physiol Biochem 2017;73:235-244.

-22 Chen X, Feng L, Jin H: Constant or fluctuating hyperglycemias increases cytomembrane stiffness of human umbilical vein endothelial cells in culture: roles of cytoskeletal rearrangement and nitric oxide synthesis. BMC Cell Biol 2013;14:22.

23 Zhou X, Cooper KL, Huestis J, Xu H, Burchiel SW, Hudson LG, Liu KJ: S-nitrosation on zinc finger motif of PARP-1 as a mechanism of DNA repair inhibition by arsenite. Oncotarget 2016;7:80482-80492.

-24 Lang JD, Jr., Chumley P, Eiserich JP, Estevez A, Bamberg T, Adhami A, Crow J, Freeman BA: Hypercapnia induces injury to alveolar epithelial cells via a nitric oxide-dependent pathway. Am J Physiol Lung Cell Mol Physiol 2000;279:L994-1002.

-25 Liu J, Lin A: Role of JNK activation in apoptosis: a double-edged sword. Cell Res 2005;15:36-42.

-26 Ghatan S, Larner S, Kinoshita Y, Hetman M, Patel L, Xia Z, Youle RJ, Morrison RS: p38 MAP kinase mediates bax translocation in nitric oxide-induced apoptosis in neurons. J Cell Biol 2000;150:335-347.

-27 Chen Q, Gao Y, Kao X, Chen J, Xue W, Xiong Y, Wang Z: SNP-induced apoptosis may be mediated with caspase inhibitor by JNK signaling pathways in rabbit articular chondrocytes. J Toxicol Sci 2012;37:157-167.

28 Liu L, Yan Y, Zeng M, Zhang J, Hanes MA, Ahearn G, McMahon TJ, Dickfeld T, Marshall HE, Que LG, Stamler JS: Essential roles of S-nitrosothiols in vascular homeostasis and endotoxic shock. Cell 2004;116:617-628.

-29 Foster MW, Hess DT, Stamler JS: Protein S-nitrosylation in health and disease: a current perspective. Trends Mol Med 2009;15:391-404.

-30 Nathan C: Nitric oxide as a secretory product of mammalian cells. FASEB J 1992;6:3051-3064.

-31 Eu JP, Liu L, Zeng M, Stamler JS: An apoptotic model for nitrosative stress. Biochemistry 2000;39:10401047.

32 Sudar E, Dobutovic B, Soskic S, Mandusic V, Zakula Z, Misirkic M, Vucicevic L, Janjetovic K, Trajkovic V, Mikhailidis DP, Isenovic ER: Regulation of inducible nitric oxide synthase activity/expression in rat hearts from ghrelin-treated rats. J Physiol Biochem 2011;67:195-204. 


\section{Cellular Physiology Cell Physiol Biochem 2018;49:1840-1855 and Biochemistry Published online: 20 September, $2018 \mid \begin{aligned} & \text { O) } 2018 \text { The Author(s). Published by S. Karger AG, Basel } \\ & \text { www.karger.com/cpb }\end{aligned}$ \\ Zeng et al.: NO Promotes Cell Apoptosis}

-33 Mao Y, Wang J, Yu F, Li Z, Li H, Guo C, Fan X: Ghrelin protects against palmitic acid or lipopolysaccharideinduced hepatocyte apoptosis through inhibition of MAPKs/iNOS and restoration of Akt/eNOS pathways. Biomed Pharmacother 2016;84:305-313.

-34 Zeng M, He W, Li L, Li B, Luo L, Huang X, Guan K, Chen W: Ghrelin attenuates sepsis-associated acute lung injury oxidative stress in rats. Inflammation 2015;38:683-690.

-35 Yang D, Liu Z, Yang Z: Ghrelin and its relation with N-terminal brain natriuretic peptide, endothelin-1 and nitric oxide in patients with idiopathic pulmonary hypertension. Cardiology 2013;124:241-245.

-36 Grossini E, Raina G, Farruggio S, Camillo L, Molinari C, Mary D, Walker GE, Bona G, Vacca G, Moia S, Prodam F, Surico D: Intracoronary Des-Acyl Ghrelin Acutely Increases Cardiac Perfusion Through a Nitric OxideRelated Mechanism in Female Anesthetized Pigs. Endocrinology 2016;157:2403-2415.

37 Virdis A, Duranti E, Colucci R, Ippolito C, Tirotta E, Lorenzini G, Bernardini N, Blandizzi C, Taddei S: Ghrelin restores nitric oxide availability in resistance circulation of essential hypertensive patients: role of NAD(P) H oxidase. Eur Heart J 2015;36:3023-3030.

-38 Slomiany BL, Slomiany A: Helicobacter pylori Induces Disturbances in Gastric Mucosal Akt Activation through Inducible Nitric Oxide Synthase-Dependent S-Nitrosylation: Effect of Ghrelin. ISRN Gastroenterol 2011;2011:308727.

-39 Misiti F, Orsini F, Clementi ME, Lattanzi W, Giardina B, Michetti F: Mitochondrial oxygen consumption inhibition importance for TMT-dependent cell death in undifferentiated PC12 cells. Neurochem Int 2008;52:1092-1099. 